\title{
PENGEMBANGAN PENGRAJIN LIMBAH BATOK KELAPA “KUJANG HANDYCRAFT" MENJADI KELOMPOK USAHA MUDA BERDIKARI
}

\author{
Edi Hendri Mulyana ${ }^{1}$, Istikhoroh Nurzaman ${ }^{2}$, Tri Lestari ${ }^{3}$, Siti Nur Uswatun Hasanah ${ }^{4}$ \\ ${ }^{1,2,3,4}$ Program Studi PGPAUD UPI Kampus Tasikmalaya \\ edihm@upi.edu/isti@upi.edu
}

Diterima: 30 Oktober 2018

Direvisi: 17 November 2018

Diterbitkan:07 Januari 2019

\begin{abstract}
Jayaratu Village Sariwangi District, Tasikmalaya Regency is one of the villages that has coconut shell craftsmen. Works that have been produced from the use of coconut shells are souvenirs, accessories, key chains, wall hangings, and utensils for eating / drinking, and so on. Based on that, the team will implement PKM through counseling, training, and guidance for coconut shell craftsmen "Kujang Handicraft" and Jayaratu Village in Tasikmalaya. The target of this PKM output is 1) Increasing knowledge, understanding and skills of coconut shell craftsmen including: a) Product design training b) Extension of promotion management, c) Extension of capital management, and 2) Availability of complete production technology facilities and infrastructure 3) Producing waste crafts coconut shell.
\end{abstract}

Keywords: Coconut Shell Waste Craftsmen, Self-Sufficient Young Entrepreneurs

\begin{abstract}
ABSTRAK
Desa Jayaratu Kecamatan Sariwangi Kabupaten Tasikmalaya salah satu desa yang mempunyai pengrajin batok kelapa. Karya yang telah dihasilkan dari pemanfaatan batok kelapa yaitu souvenir, accessories, gantungan kunci, hiasan dinding, serta perlengkapan alat makan/minum, dan lain sebagainya. Berdasarkan hal itu, maka tim akan melaksanakan PkM melalui kegiatan penyuluhan, pelatihan, dan pembinaan terhadap pengrajin batok kelapa "Kujang Handycraft" dan masyarakat desa jayaratu Tasikmalaya. Target luaran PkM ini adalah 1) Meningkatkan pengetahuan, pemahaman serta keterampilan pengrajin batok kelapa meliputi: a) Pelatihan design produk b) Penyuluhan manajemen promosi, c) Penyuluhan manajemen permodalan, dan2) Tersedianya sarana dan prasarana teknologi produksi yang lengkap 3) Dihasilkannya kerajinan limbah batok kelapa.
\end{abstract}

Kata Kunci: Pengrajin Limbah Batok Kelapa, Usaha Muda Berdikari 


\section{PENDAHULUAN}

Kujang Handycraft merupakan pengrajin batok kelapa di Dusun Peuteuyjaya Desa Jayaratu Kecamatan Sariwangi Kabupaten Tasikmalaya yang berdiri pada tahun 2014. Banyak berbagai karya yang telah dihasilkan dari pemanfaatan batok kelapa ini yaitu souvenir, accessories, gantungan kunci, hiasan dinding, perlengkapan alat makan/minum dan lain sebagainya. Namun masih ada permasalahan yang dihadapi oleh pengrajin tersebut yaitu karena keterbatasan tempat, alat, serta tenaga kerja membuat usaha pengrajin batok kelapa kewalahan dengan alat ukir sederhana, gunting, dan pisau. Sedangkan banyak konsumen yang memesan souvenir khususnya gantungan kunci sampai dengan memesan ratusan hingga ribuan karena, keterbatasan tersebut Kujang Handycraft tidak bisa memenuhi kenginan konsumen.

Masalah klasik yang di hadapi pengrajin batok kelapa ini adalah kurangnya permodalan, tidak ada alat perlengkapan yang menunjang, sumber daya manusia yang kurang dan belum paham, sarana dan prasarana teknologi produksi, serta sarana promosi atau pemasaran yang minim. maka, [1] Eksistensi UU No. 6 Tahun 2014 secara tegas menjelaskan mengenai pemberdayaan masyarakat sebagaimana tertuang dalam pasal 1 ayat 12. Pasal tersebut berbunyi: "Pemberdayaan masyarakat desa adalah upaya mengembangkan kemandirian dan kesejahteraan masyarakat dengan meningkatkan pengetahuan, sikap, keterampilan, perilaku, kemampuan, kesadaran, serta memanfaatkan sumber daya melalui penetapan kebijakan, program, kegiatan, dan pendampingan yang sesuai dengan esensi masalah dan prioritas kebutuhan masyarakat desa."

Merujuk pada peraturan perundang-undangan tentang pemberdayaan masyarakat dan melihat permasalahan yang dihadapi oleh pengrajin batok kelapa "Kujang Handycraft" di Dusun Peteuyjaya Desa Jayaratu Pada akhirnya, ingin mengimplikasikan peraturan perundangan tersebut serta dapat membantu pengrajin batok kelapa dengan dibuktikan secara empiris, maka dari itu tim pengabdian dari UPI Kampus Tasikmalaya merasa perlu untuk memberikan solusi dengan melaksanakan pengabdian berupa penyuluhan ataupun pelatihan kepada pengrajin Batok Kelapa "Kujang Handycraft" dan masyarakat Dusun Peteuyjaya Desa Jayaratu Kecamatan Sariwangi Kabupaten Tasikmalaya oleh tim Pkm dan narasumber.

\section{METODE}

Adapun model pelatihan yang digunakan terkait pengembangan pengrajin limbah batok kelapa "kujang handycraft" menjadi kelompok usaha muda berdikari adalah [2] model pelatihan dari Treadway Pakker dengan tahapan: 1) Analisis kebutuhan merupakan tahap awal sebagai upaya menentukan program kegiatan pengabdian analisis kebutuhan pengrajin limbah batok kelapa "Kujang Handycraft" antara lain: [3] Proses analisis dilakukan dengan identifikasi masalah menggunakan teknik analisis SWOT kekuatan (strength), kelemahan (weaknesses), peluang (opportunities), dan ancaman (threats); 2) Tujuan Pelatihan dan Pembinaan (Develop Training Objective); 3) Merancang Kurikulum Pelatihan (Designing Training Curriculum); 4) Metode Pelatihan (Designing Training Methode); 5) Pendekatan Evaluasi Pelatihan (Designing Training Evaluation Approach); 6) Implementasi Program (Implement Training Program); 7) Pengukuran Hasil Pelatihan (Measure Training Result). Adapun khalayak sasaran dari program pengabdian ini yaitu mitra terkait dan masyarakat Desa Jayaratu Kecamatan Sariwangi Kabupaten Tasikmalaya. Langkah-langkah kegiatan pengabdian kepada masyarakat ini adalah 1) 
Persiapan kegiatan pengabdian, 2) Pelaksanaan kegiatan pengabdian antara lain : a) Pelatihan design produk b) Penyuluhan manajemen promosi, c) Penyuluhan manajemen permodalan, dan d) Penyediaan alat dan bahan. 3) Monitoring dan evaluasi program pengabdian; dan 4) Tindak lanjut.

\section{III.HASIL DAN PEMBAHASAN}

\section{a. Pelatihan Design Produk}

Seiring dengan perkembangan zaman dan munculnya produk-produk berbagai kerajinan berupa accessories ataupun alat berbahan limbah batok kelapa. Maka dari itu diperlukan inovasi terkait produk bahan dasar batok kelapa agar lebih menarik oleh para penikmat seni dan konsumen. Kegiatan pelaksanaan design produk ini dilaksanakan bersamaan dengan pembuakaan kegiatan sosialisai. Adapun untuk narasumbernya langsung oleh ahli yang berkompeten dalam bidangnya. Tim PKM sejatinya membantu dalam hal design dan segi teknologinya saja, terkait proses pembuatan produk secara teknisnya dilaksanakan oleh mitra.

\section{b. Penyuluhan Manajemen Promosi}

Kegiatan promosi merupakan kegiatan selanjutnya setelah suatu barang diproduksi. Dalam hal promosi ini [3] perusahaan harus merencanakan berbagai cara untuk mempromosikan barang/jasa hasil produksinnya, Adapun untuk materi yang disampaikan dalam penyuluhan manajemen promosi yaitu: a) Apa itu promosi b) Fungsi promosi c) Strategi promosi d) Tujuan promosi e) Cara-cara promosi f) Perbedaan promosi dan pemasaran. Narasumber dari kegiatan penyuluhan manajemen promosi ini dilaksanakan oleh tim PkM.

\section{c. Penyuluhan Manajemen Permodalan}

[4] Modal merupakan salah satu hal terpenting dalam sebuah perusahaan. Dengan modal perusahaan dapat melaksanakan aktivitas produksi dan aktivitas bisnis lainnya, tanpa modal (berbentuk uang) perusahaan tetap berjalan, namun aktivitasnya sangat terbatas. Adaun materi yang disampaikan dalam penyuluhan ini yaitu: a) Pengertian modal b) Sumber-sumber modal c) Jenis-jenis modal d) Kelebihan dan kekurangan modal sendiri e) Kelebihan dan kekurangan modal pinjaman. Adapun narasumber yang diundang yaitu ari pihak Dosen.

\section{d. Penyediaan alat dan Bahan}

Sarana dan Prasarana (Alat dan Bahan) yang diberikan kepada mitra tentunya disesuaikan dengan kebutuhan mitra berdasarkan ajuan yang disampaikan oleh mitra. Pengadaan alat dan bahan ini tentunya disesuaikan dengan anggaran yang tersedia.

\section{IV.SIMPULAN}

Pengabdian kepada masyarakat terkait program pengembangan pengrajin limbah batok kelapa "Kujang Handycraft dengan berupa penyuluhan dan pelatihan mendapat respon positif baik itu dari pemerintahan Kecamatan Sariwangi, pemerintahan Desa Jayaratu ataupun warga Desa Jayaratu Kecamatan Sariwangi 
Kabupaten Tasikmalaya. Kegiatan ini diawali dengan koordinasi antara tim pengabdian dan pengrajin limbah batok kelapa 'Kujang Handycraft'. Setelah ada kesepatakan, maka langkah selanjutnya adalah pelaksanaan. program pengabdian terkait pengembangan pengrajin limbah batok kelapa 'Kujang Handycraft'.

Untuk meningkatkan pengetahuan, pemahaman dan keterampilan pengrajn batok kelapa "Kujang Handycraft" terkait: a) Pelatihan design produk b) Penyuluhan manajemen promosi, c) Penyuluhan manajemen permodalan, dan d) Penyediaan alat dan bahan, berjalan dengan lancar walaupun masih ada kekurangan dan memerlukan tindak lanjut dari kegiatan pengabdian ini. Adapun sarannya yaitu bagi Pemerintahan Kecamatan Sariwangi Kabupaten Tasikmalaya dan pengrajin limbah batok kelapa diharapkan bahwa program pengabdian ini ditindak lanjuti sehingga program pengembangan pengrajin limbah batok kelapa "Kujang Handycraft" dapat terlaksana dengan baik, dan bagi masyarakat, semoga dapat memanfaatkan hasil penyuluhan dan pelatihan yang telah diberikan sebagai bekal dasar dalam megembangkan kerajinan dari bahan dasar limbah batok kelapa.

\section{DAFTAR PUSTAKA}

1. Anoraga, Pandji. (2008). Manajemen Bisnis. Jakarta : Rineka Cipta.

2. LPPM UPI. (2017). Panduan Pelaksanaan Kegiatan Penelitian dan Pengabdian Kepada Masyarakat Di Lingkungan Universitas Pendidikan Indonesia Tahun 2017. Bandung: UPI.

3. Rohaniyah, S. (2005). Pola Permberdayaan Pemuda dengan Pelatihan Budi Daya Ayam Arab di BPPLSP Regional III Jawa Tengah. Skripsi Tidak Diterbitkan UNNES Semarang.

4. Wahjono S. Imam. (2008). Manajemen Tata Kelola Organisasi Bisnis. Jakarta : Indeks. 